\title{
Morphological alterations in salivary glands of Rhipicephalus sanguineus ticks (Acari: Ixodidae) exposed to neem seed oil with known azadirachtin concentration
}

\author{
R.N. Remedio ${ }^{a}$, P.H. Nunes ${ }^{a}$, L.A. Anholeto ${ }^{a}$, P.R. Oliveira ${ }^{a}$, I.C.G. Sá ${ }^{b}$, \\ M.I. Camargo-Mathias ${ }^{\mathrm{a}, *}$ \\ a UNESP, Avenida 24 A, 1515, 13506-900 Rio Claro, SP, Brazil \\ b UFSCar, Rodovia Washington Luís, Km 235, 13565-905 São Carlos, SP, Brazil
}

\section{A R T I C L E I N F O}

\section{Article history:}

Received 6 August 2015

Received in revised form 14 January 2016

Accepted 15 January 2016

Available online 19 January 2016

\section{Keywords:}

Morphology

Brown dog tick

Acaricide

Control

Phytochemical

\begin{abstract}
A B S T R A C T
Neem (Azadirachta indica) has attracted the attention of researchers worldwide due to its repellent properties and recognized effects on the morphology and physiology of arthropods, including ticks. Therefore, this study aimed to demonstrate the effects of neem seed oil enriched with azadirachtin on salivary glands of Rhipicephalus sanguineus ticks, targets of great veterinary interest because of their ability to transmit pathogens to dogs. For this, $R$. sanguineus semi-engorged females were subjected to treatment with neem seed oil, with known azadirachtin concentrations (200, 400 and 600 ppm). After dissection, salivary glands were collected and evaluated through morphological techniques in light microscopy, confocal scanning laser microscopy and transmission electron microscopy, so that the possible relation between neem action and further impairment in these ectoparasites feed performance could be established. Neem oil demonstrated a clear dose-dependent effect in the analyzed samples. The agranular (type I) and granular acini (types II and III) showed, particularly in individuals treated with the highest concentrations of the product, cells with irregular shape, intense cytoplasmic disorganization and vacuolation, dilation of rough endoplasmic reticulum lumen, besides alterations in mitochondrial intermembrane space. These morphological damages may indicate modifications in salivary glands physiology, demonstrating the harmful effects of compounds present in neem oil on ticks. These results reinforce the potential of neem as an alternative method for controlling $R$. sanguineus ticks, instead of synthetic acaricides.
\end{abstract}

(c) 2016 Elsevier Ltd. All rights reserved.

\section{Introduction}

Rhipicephalus sanguineus is undoubtedly the most important species involved in the transmission of infectious agents to dogs (Dantas-Torres, 2010). Those specimens belonging to tropical and subtropical lineages are capable of transmiting Ehrlichia canis, causative agent of the canine monocytic ehrlichiosis, and Babesia canis, responsible for transmitting canine babesiosis (Blagburn and Dryden, 2009). Besides, some research indicate that they may be potential vectors of Leishmania chagasi, which causes the canine visceral leishmaniosis (Dantas-Torres, 2010) and Rickettsia rickettsii, causative agent of Rocky Mountain spotted fever (Cunha

\footnotetext{
* Corresponding author at: Universidade Estadual Paulista "Júlio de Mesquita Filho", Av. 24-A, 1515, P.O. Box 199, Departamento de Biologia, Bela Vista, Rio Claro São Paulo 13506-900, Brazil.

E-mail address: micm@rc.unesp.br (M.I. Camargo-Mathias).
}

et al., 2009). These ticks can be found in dogs living in both urban and rural areas, being highly adapted to live in human dwellings (Blagburn and Dryden, 2009; Dantas-Torres, 2010). Although dogs are their preferred hosts, $R$. sanguineus ticks may occasionally parasite a wide variety of domestic and wild animals (Dantas-Torres et al., 2006; Blagburn and Dryden, 2009), being found even in humans (Carpenter et al., 1990; Manfredi et al., 1999; Uspensky and Ioffe-Uspensky, 2002).

For this reason, there is a growing need for the development of new methods for tick control. In human and veterinary health field, tick control is performed mainly by the use of chemical compounds with acaricide action (Flamini, 2003; Jonjejan and Uilenberg, 2004), usually formulated based on synthetic products (Alves et al., 2012). However, such substances are toxic, causing environmental pollution and presenting high cost (Jonjejan and Uilenberg, 2004), besides promoting the selection of resistant strains of ticks (Blagburn and Dryden, 2009; Rosado-Aguilar et al., 2010). 
Substances obtained from plant extracts, however, have low cost, few residual effects and generate low incidence of resistance development (Rosado-Aguilar et al., 2010). In this sense, the use of leaves, fruits and seeds extracted from the neem tree (Azadirachta indica) has been intensified, due to the presence of biologically active ingredients with various modes of action (Vietmeyer, 1992; Atawodi and Atawodi, 2009). This Meliaceae is original from the South and Southeast of Asia, being also found in tropical and subtropical areas of America, Africa and Australia (Schmutterer, 1990). It is capable of controlling species that are considered plagues, apparently without harming the human being, animals or beneficial insects (Vietmeyer, 1992). Its most important and predominant active principle, azadirachtin, presents a broad action spectrum, including alterations in growth and reproduction of arthropods (Vietmeyer, 1992; Schmutterer, 1990; Brahmachari, 2004). Neem derivatives do not persist in the environment, once they are degraded by ultraviolet rays and rain (Brahmachari, 2004). For this reason, these compounds are considered excellent substitutes for many synthetic pesticides (Vietmeyer, 1992).

Under different formulations, neem extracts showed expressive effects on the control of several tick species, such as Hyalomma anatolicum excavatum (Abdel-Shafy and Zayed, 2002), Rhipicephalus (Boophilus) decoloratus (Choudhury, 2009), and Rhipicephalus (Boophilus) microplus (Srivastava et al., 2008; Broglio-Micheletti et al., 2010). Moreover, in $R$. sanguineus ticks, aqueous extracts of neem leaves caused significant morphological alterations in ovaries (Denardi et al., 2010, 2011, 2012; Remedio et al., 2015), synganglion and integument (Remedio et al., 2014).

Thus, the present work aimed to evaluate the effects of the oil extracted from neem seeds ( $A$. indica) on the morphology of the salivary glands of $R$. sanguineus female ticks. These organs are remarkably versatile, vital for the biological success of these animals (Sauer et al., 1995). To this end, such structures were analyzed using techniques in conventional light microscopy, confocal laser scanning microscopy and transmission electron microscopy, in order to generate information that can complement the results previously obtained for $R$. sanguineus treated with neem and reinforce the use of neem extracts in the control of this tick species.

\section{Material and methods}

\subsection{R. sanguineus ticks}

Unfed male and female ticks were obtained directly from the colony maintained in a Biological Oxygen Demand (BOD) incubator under controlled conditions $\left(25 \pm 1{ }^{\circ} \mathrm{C}, 80 \%\right.$ humidity, in a $12 \mathrm{~h}$ photoperiod), in the Biosciences Institute vivarium of São Paulo State University (UNESP), Rio Claro/SP, Brazil.

\subsection{Azadirachta indica (neem)}

Neem oil was provided by Professor Moacir Rossi Forim, from Universidade Federal de São Carlos (UFScar). Neem seeds (2,5 kg) were ground in a Tecnal TE 631/2 mill and, then, subjected to an extraction process with hexane (5 extractions with duration of 3 days each), in order to obtain the neem oil. After this, the seeds went through a methanol extraction by 3 sequent extractions performed using an Ultra-Turrax T-20. After filtration, the solvent was evaporated under reduced pressure to provide an extract rich in azadirachtin, which was subsequently mixed with the previous extracted oil in order to enrich it with azadirachtin. The measurement of azadirachtin concentration in the crude extract of neem oil was made through the same procedures described by Forim et al. (2010). A concentration of 1000 parts per million (ppm) of azadiractin in the crude extract was determined, and from this oil the dilutions used in this experiment were made.

\subsection{Experimental procedures}

\subsubsection{Preparation of neem dilutions}

The crude oil extracted from neem seeds was diluted at concentrations of 20,40 and $60 \%$ in a $10 \%$ aqueous solution of ethanol, according to an adaptation of the methodology described by Ndumu et al. (1999). Thus, it was possible to obtain dilutions with specific concentrations of azadirachtin: $200 \mathrm{ppm}$ (20\%), $400 \mathrm{ppm}$ (40\%) and $600 \mathrm{ppm}$ (60\%). The solutions were mixed on a magnetic stirrer and applied topically on ticks. The dilutions were made daily during the experiment, and kept in a light-protected recipient, in order to avoid alterations of the acaricidal properties of neem oil.

\subsubsection{Bioassay}

A total of sixty couples of $R$. sanguineus were released inside special feeding chambers set on the back of naive New Zealand White female rabbits (without prior exposure to tick infestation), following the methodology described by Bechara et al. (1995). Five rabbits were used in this experiment, one for each group $(\mathrm{CI}, \mathrm{CII}, \mathrm{TI}$, TII and TIII). The procedures for application of neem dilutions were performed inside these feeding chambers, during engorgement of females.

Five groups were established in this experiment: Control Groups (CI and CII) and Treatment Groups (TI, TII and TIII). In the Treatment Groups, the solutions of neem oil were applied topically on ticks attached on the back of rabbits with a soft brush for three days, twice a day. The applications begun $24 \mathrm{~h}$ after attachment of tick to the host, at the concentrations of $20 \%$ (TI), $40 \%$ (TII) and $60 \%$ (TIII). The ticks from Control Groups ( $\mathrm{CI}$ and $\mathrm{CII}$ ) were subjected to the same procedure, with applications of distilled water and $10 \%$ aqueous ethanol, respectively. Approximately $5 \mathrm{~mL}$ of solution was used in each application. On the fourth day of infestation, semi-engorged females were collected and maintained under controlled conditions in a BOD incubator before dissection for removal of samples. The collected ticks were dissected under a Leica EZ4 stereomicroscope in Petri dishes containing phosphate-buffered saline (PBS) solution ( $\mathrm{NaCl} 0.13 \mathrm{M}, \mathrm{Na}_{2} \mathrm{HPO}_{4} 0.017 \mathrm{M}, \mathrm{KH}_{2} \mathrm{PO}_{4} 0.02 \mathrm{M}, \mathrm{pH} 7.2$ ) for withdrawal of salivary glands samples.

All experimental procedures performed in this study were approved by the Ethics Committee in Animal Use, CEUA, UNESP, Rio Claro/SP, Brazil, protocol number 2206, decision number 021/2012.

\subsection{Morphological analysis}

\subsubsection{Light microscopy (LM)}

For histological analysis, the collected material was immediately fixed in formaldehyde (4\% paraformaldehyde solution) for $72 \mathrm{~h}$ and, then, transferred to sodium phosphate buffer solution $(\mathrm{NaCl}$ $0.13 \mathrm{M}, \mathrm{Na}_{2} \mathrm{HPO}_{4} 0.017 \mathrm{M}, \mathrm{KH}_{2} \mathrm{PO}_{4} 0.02 \mathrm{M}, \mathrm{pH} 7.2$ ), for $24 \mathrm{~h}$. The samples were subsequently subjected to dehydration in an ascending series of ethanol (70, 80, 90 and 95\%, for 20 min in each solution), overnight infiltration in Leica historesin, followed by polymerization with Leica historesin plus a hardener agent.

The resin blocks containing the material were sectioned on a Leica RM2255 microtome (thickness: $3 \mu \mathrm{m}$ ), and the sections subjected to staining with hematoxylin and eosin technique (HE), for the observation and description of the general morphology of the tissue (Junqueira and Junqueira, 1983). The microscopic slides obtained were mounted in Canada synthetic balsam and the material was photographed in a Leica DM150 light photomicroscope, equipped with a Leica ICC50HD camera, by means of the Leica LAS v.3.8 software. 


\subsubsection{Laser scanning confocal microscopy (LSCM)}

The collected samples were immediately fixed in formaldehyde (4\% paraformaldehyde solution) for $72 \mathrm{~h}$, washed in $\mathrm{PBS}(\mathrm{NaCl}$ $0.13 \mathrm{M}, \mathrm{Na}_{2} \mathrm{HPO}_{4} 0.017 \mathrm{M}, \mathrm{KH}_{2} \mathrm{PO}_{4} 0.02 \mathrm{M}, \mathrm{pH} 7.2$ ) twice for $5 \mathrm{~min}$ and then permeabilized with $0.1 \%$ Triton-X for 20 min. After two washes of $5 \mathrm{~min}$ each, the material was incubated with a solution of "Alexa Fluor 488 Phalloidin" for $30 \mathrm{~min}$ at room temperature in a covered container, for the observation of actin filaments. The samples were washed in PBS (twice, 5 min each), stained with propidium iodide at $10 \mu \mathrm{g} / \mathrm{mL}$ for $30 \mathrm{~min}$ in the dark, for identification of nucleic acids. After, the material was washed again in PBS (twice, 5 min each) and mounted using mounting medium Prolong ${ }^{\circledR}$ Gold reagent. The images were obtained with a Leica TCS SP5II Laser Confocal Scanning Microscopy, and analyzed by means of the Leica LAS AF software.

\subsubsection{Transmission electron microscopy (TEM)}

For ultrastructural analysis, the collected salivary gland samples were fixed in glutaraldehyde $2.5 \%$ in sodium cacodylate buffer $0.1 \mathrm{M}$ ( $\mathrm{pH} 7.2$ ), during $72 \mathrm{~h}$. Next, the material was washed twice in $0.1 \mathrm{M}$ sodium cacodylate buffer ( $15 \mathrm{~min}$ each time) and then postfixed in osmium tetróxide $\left(\mathrm{OsO}_{4}\right)$ for $2 \mathrm{~h}$. The samples were, then, washed twice again in $0.1 \mathrm{M}$ sodium cacodylate buffer ( $15 \mathrm{~min}$ each time) and immersed in a $10 \%$ aqueous ethanol solution for $15 \mathrm{~min}$. The material was contrasted in 1\% uranyl acetate, dehydrated in an ascending series of acetone (50, 70, 90 and $100 \%$, for 5 min in each solution) and then dipped in a mixture of acetone and Epon-Araldite resin (1:1) for $12 \mathrm{~h}$, embedded in Epon-Araldite resin for $24 \mathrm{~h}$ and included in Epon-Araldite resin plus a catalyser at $60^{\circ} \mathrm{C}$. Ultrathin sections, obtained using an ultramicrotome Leica Reichert Supernova were placed on copper grids and contrasted in uranyl acetate $4 \%$, during $45 \mathrm{~min}$, and lead citrate, for $10 \mathrm{~min}$ (Reynolds, 1963). The material was observed and photographed in a Philips CM100 transmission electron microscope (TEM, operating at an accelerating voltage of $80 \mathrm{kV}$ ) equipped with a Veleta camera, by means of the iTEM software (v. 5.2).

\section{Results}

The morphological evaluation of the salivary glands of $R$. sanguineus ticks allowed the observation of agranular (type I) and granular (types II and III) acini. For didactic purposes, the description of the results was made in a general way, without identifying the specific types of cells composing each acinus.

\subsection{Conventional light microscopy (CLM)}

No differences were observed between groups $\mathrm{CI}$ and $\mathrm{CII}$. The agranular acini (Fig. 1A) comprised a central cell and several peripheral cells and typically presented a round-shaped and slightly irregular aspect. The central cell presented a rounded nucleus, slightly stained in purple by hematoxylin and located next to the center of the acinus, while the peripheral cells showed smaller but also slightly stained nuclei. It was not possible to observe the nucleoli and the membranes of the cells. In general, the cytoplasm of the peripheral cells showed strong acidophilia, being more intensely pink stained by eosin. The type II granular acini (Fig. 1B) presented rounded shape, being constituted by cells with different secretion granules. These granulations varied in the size, color intensity and staining affinity. However, some cells presented pinkish agranular and acidophilous cytoplasm. The nuclei in general were slightly stained by hematoxylin, presenting rounded shape and different sizes according to the type of the cell. It was not possible to observe the nucleoli. The type III granular acini (Fig. 1C) presented typical morphology, with rounded shape and secretory cells with different cytoplasmic granules. These structures exhibited different sizes, in addition to differences in the intensity of color and staining affinity. However, as in the type II acini, some cells did not present granulations, having an acidophilous cytoplasm, pink stained by eosin. Rounded nuclei, weakly stained by hematoxylin, could be observed. The nucleoli could be visualized in some cells.

In group TI, no morphological differences were observed in type I acini in relation to the individuals belonging to control groups (Fig. 1G). The type II acini (Fig. 1H) showed general characteristics similar to groups $\mathrm{CI}$ and CII, although subtle loss of cell contact was observed in some cases. The type III acini (Fig. 1I) presented irregular shape and evident areas of vacuolation throughout the cytoplasm, mainly in the cells without secretion granules.

In group TII, the agranular acini (Fig. 1J) showed typical morphology, presenting no differences in relation to control groups. The granular type II acini (Fig. $1 \mathrm{~K}$ ) presented similar morphology in relation to group TI, with loss of cell contact. In addition, evident cytoplasmic vacuolation was observed, mainly in the cells without secretion granules. The type III acini (Fig. 1L) presented a completely irregular shape, with areas of intense vacuolation throughout the whole cytoplasm, mainly around the nuclei of the cells with no secretion granules. A subtle increase in the intercellular space was also observed, similarly to the type II acini. In some secretory cells, an apparent fusion, or rupture in the secretion granules, was observed. These granules consequently lost their typical rounded shape and were less stained by eosin.

In group TIII, no morphological differences were observed in the agranular acini (Fig. 1M) when compared with the ones belonging to the control group. However, in the granular type II acini (Fig. 1N), the cytoplasmic vacuolation was more intense, mainly in the cells without secretion granules. In addition, it was possible to visualize an increase in the intercellular spaces, similarly to groups TI and TII. The type III acini (Fig. 10) presented a completely irregular shape, similarly to group TII. The vacuolated regions were more intensely and frequently observed, as well as the loss of cell contact. The granules of the secretory cells could no longer be individually observed, being apparently fused or ruptured and also weakly stained by eosin, resulting in a more homogeneous cytoplasm.

\subsection{Confocal laser scanning microscopy (CLSM)}

The observation of samples stained with propidium iodide in fluorescence allows the observation of nucleic acids (Suzuki et al., 1997), while phalloidin, which attaches to the actin filaments, is used for the evaluation of the cytoskeleton architecture of the cells (Cooper, 1987). This technique, however, did not allow the identification of each type of acinus and, for this reason, the results were described for the organ as a whole. In the individuals belonging to groups CI (Fig. 2A,B) the acini cells presented a reddish cytoplasm, resulting from staining by propidium iodide. Secretion granules, when present, were not reactive to the stain. Cell nucleus presented weak red stain varying according to the level of chromatin condensation. In the peripheries of the cells, as well as around the acini lumen and also in the excretory ducts, an intense stain in green by phalloidin was observed, evidencing the presence of cytoskeleton elements and allowing the observation of the rounded shape of the acini. In group CII (Fig. 2C,D), however, propidium iodide staining was more intense in all acini, while phalloidin showed the same staining pattern as in group $\mathrm{CI}$.

The acini of groups TI (Fig. 2E,F), TII (Fig. 2G,H) and TIII (Fig. 2I,J) showed more intense staining with phalloidin when compared to controls groups, with no differences between them. This allowed the observation of the irregular aspect of the acini belonging to individuals subjected to the treatment. Propidium iodide staining, in turn, was the same as observed in group CII. 


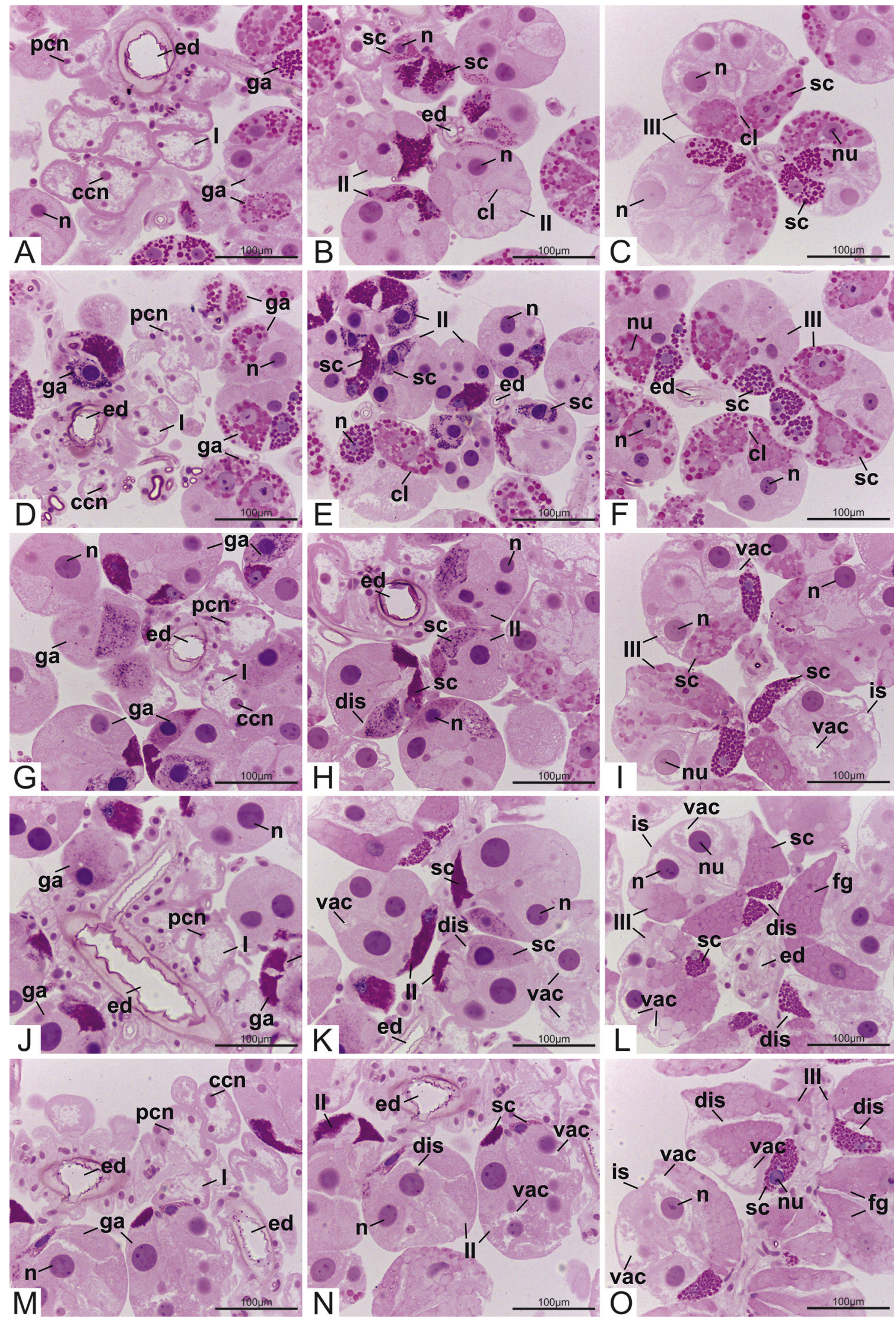

Fig. 1. Histological sections of type I (A, D, G, J, M), type II (B, E, H, K, N) and type III (C, F, I, L, O) acini from salivary glands of R. sanguineus ticks, stained by hematoxylin-eosin and examined under conventional light microscopy. (A-C) Control Group I; (D-F) Control Group II; (G-I) Treatment Group I; (J-L) Treatment Group II; (M-O) Treatment Group III. Legends: (ccn) central cell nucleus, (cl) cell limit, (dis) dilated intercellular space, (ed) excretory duct, (fg) fused granules, (ga) granular acini, (I) type I acinus, (II) type II acinus, (III) type III acinus, (is) irregular surface, (n) nucleus, (nu) nucleolus, (pcn) peripheral cell nucleus, (sc) secretory cell, (vac) vacuolation. Bars: (A-I) $100 \mu \mathrm{m}$. 


\subsection{Transmission electron microscopy (TEM)}

No differences were observed between the individuals belonging to groups $\mathrm{CI}$ and $\mathrm{CII}$. In these groups, the agranular acini (Figs. $3 A, B$ and $4 A, B$ ), showed a large central cell and several peripheral cells supported by a homogeneous basal lamina with moderate electron density. The central cell showed irregular format, with membrane folding or irregularities, and a finely granular chromatin, whose electron density varied according to the condensation degree. Cytosol presented low electron density, containing a large number of highly electron dense mitochondria, relatively large and elongated. Endoplasmic reticulum, Golgi apparatus and ribosomes could not be visualized. The peripheral cells presented smaller nuclei when compared with the central cell. They also showed several cytoplasmic processes emerging from the body of the cell and forming a basal labyrinth in contact with the basal lamina. The cytosol inside these processes presented mitochondria with similar shapes, electron densities and sizes in relation to those of the central cell. The granular acini (type II and type III) showed rounded and regular shape. In these acini, several cellular types could be visualized, with characteristic secretion granules, according to the physiological state of the ticks analyzed. The nucleus, in general, showed irregular membrane, granular chromatin with low electron density and also a granular, rounded and highly electron dense nucleolus (Figs. 3C and 4B). Heterochromatin could not be observed in the secretory cells, only the euchromatin. The secretion granules presented a great variety of characteristics, depending on the cell type: rounded shape, showing irregularities, highly electron dense (Figs. 3C,D and 4B,C); spherical shape, containing highly electron dense subunits immersed in a less electron dense matrix (Figs.
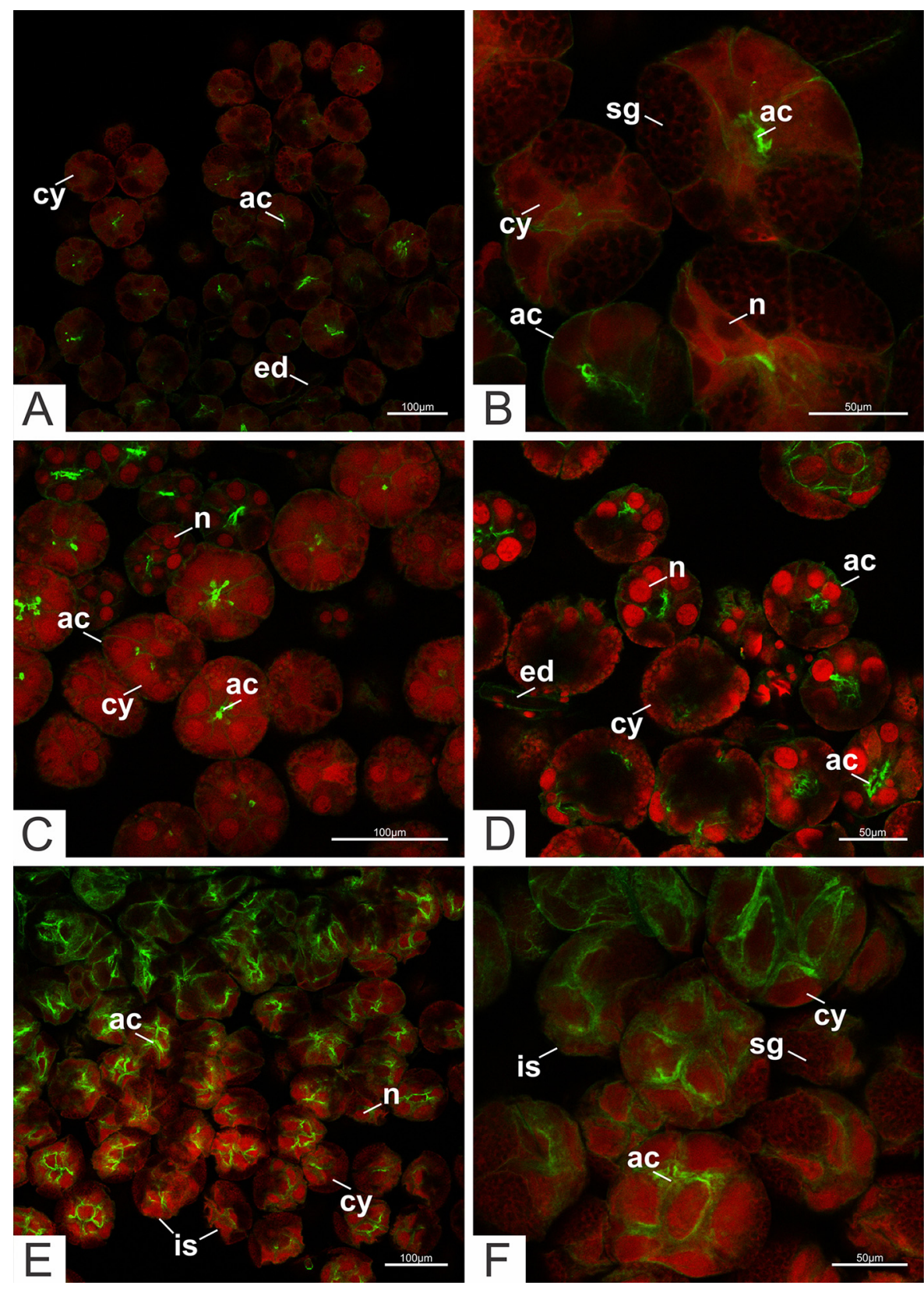

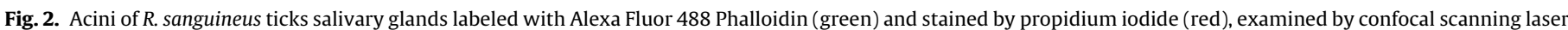

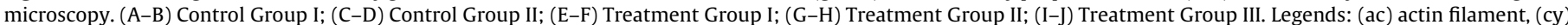

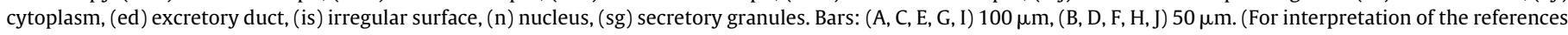
to color in this figure legend, the reader is referred to the web version of this article.) 

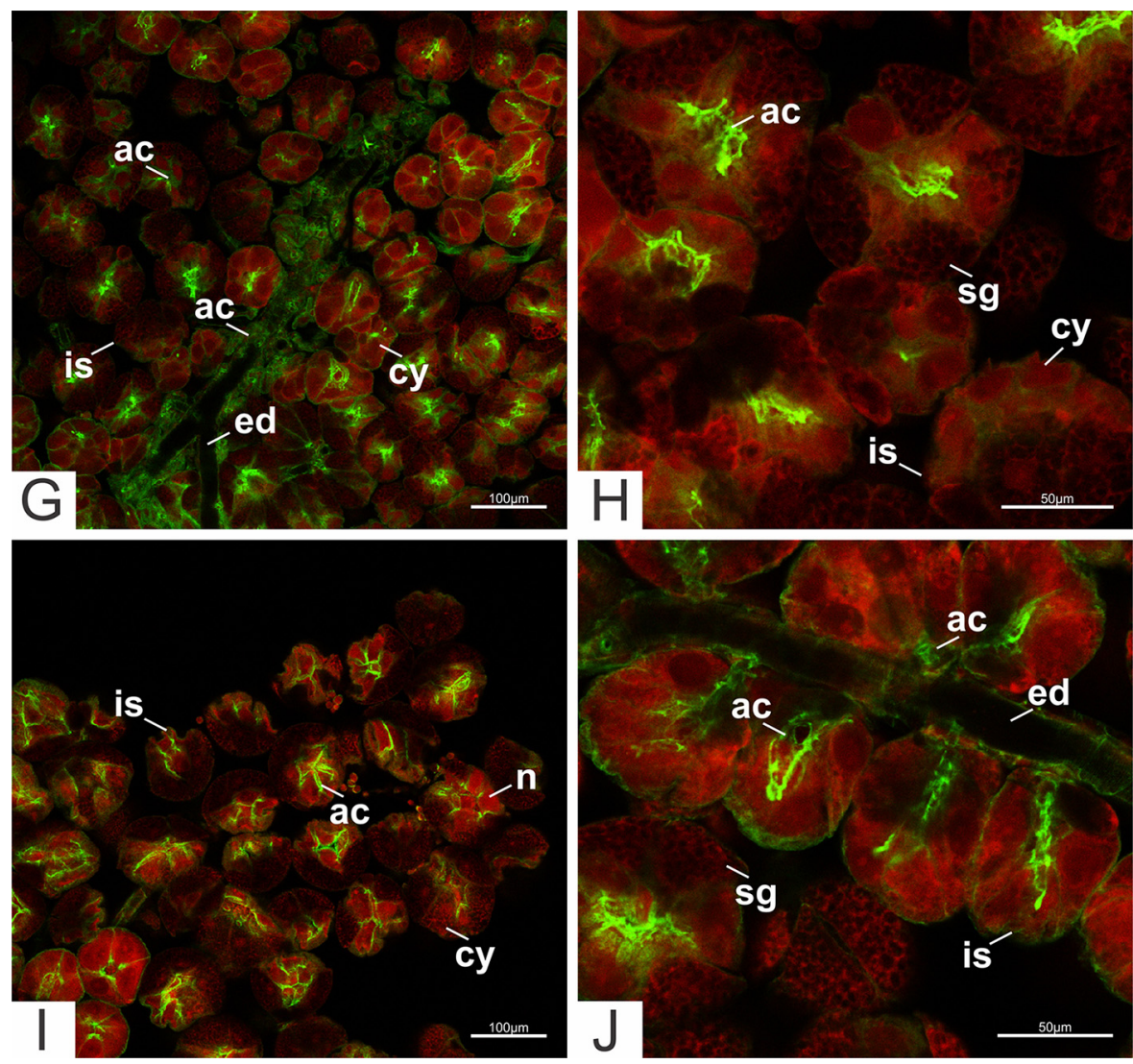

Fig. 2. (Continued).)

3E,F and 4E); spherical shape without subunits, relatively large and showing moderate electron density (Figs. $3 \mathrm{G}$ and $4 \mathrm{~F}$ ); and irregular shape, with weakly electron dense subunits immersed in a more electron dense matrix (Figs. $3 \mathrm{H}$ and 4D). Cisternae of the rough endoplasmic reticulum (RER) could be observed surrounding these granules, with vesicular aspect and constituted by granular material slightly more electron dense in relation to the cytosol (Figs. 3D,F and 4E,F). Rounded or elongated mitochondria were observed among the cisternae, depending on the type of cell, with a large number of cristae and highly electron dense matrix. The intermembrane spaces were enlarged most of the times (Figs. 3D and $4 \mathrm{~F})$.

No significant alterations were observed in the agranular acini of the individuals belonging to group TI. In general, the granular acini cells showed irregular shape and a slightly vacuolated cytoplasm (Fig. 5A-C). However, these alterations were not observed in the whole tissue. Secretory granules with electron lucid areas and disorganized content were observed in some cells (Fig. 5D,E). In addition, the RER lumen was occasionally enlarged and highly electron lucid. The intermembrane space of the mitochondria was dilated in some cells (Fig. 5F).

The alterations observed in group TII were more significant and affected a larger extension of the tissue, in relation to group TI. The central cells of some agranular acini presented electron lucid and completely disorganized cytoplasm; however, the nucleus did not show any alterations (Fig. 6A). Most of the granular acini cells presented regions with evident cytoplasmic vacuolation, observed as large irregular and electron lucid spaces in which no organelles were observed (Fig. 6B,C). In addition, several cell types showed highly electron lucid and enlarged RER cisterns, without granular content in their interior (Fig. 6D,E). Similarly to group TI, enlarged intermembrane spaces were observed in mitochondria (Fig. 6F).
In individuals belonging to group TIII, the alterations resulting from the treatment with neem oil were more evident in relation to groups TI and TII, being observed in almost the whole tissue. In the agranular acini, the central cells showed intense cytoplasmic vacuolation, demonstrated by the highly electron lucid aspect of the cytosol. The nucleus was completely irregular and few organelles could be visualized (Fig. 7A). In the granular acini, the cells presented highly electron lucid and irregular regions in cytoplasm, indicating cytoplasmic vacuolation or disorganization (Fig. 7B,C). Enlarged, highly electron lucid and practically empty RER cisterns were also observed (Fig. 7D,E). Mitochondria showed enlarged intermembrane space when compared to groups TI and TII (Fig. 7F).

\section{Discussion}

Neem extracts are unique, mainly because they are able to cause subtle alterations in the behavior and physiology of many arthropods, impairing their reproductive and feeding processes, affecting metamorphosis (Vietmeyer, 1992; Brahmachari, 2004), besides causing recognized morphological effects in the ovary (Denardi et al., 2010, 2011, 2012), synganglion and integument (Remedio et al., 2014) of $R$. sanguineus ticks.

In the present study, it is possible that the substances present in neem seed extracts crossed the integument of the $R$. sanguineus ticks, reaching hemolymph and internal organs. According to Remedio et al. (2014), R. sanguineus ticks exposed to topical applications of aqueous neem leaf extract showed subcuticle thinning and cytoplasmic disorganization and vacuolation in epithelial cells of integument, indicating active absorption of the product by the body surface and thus corroborating the results obtained in the present study. 

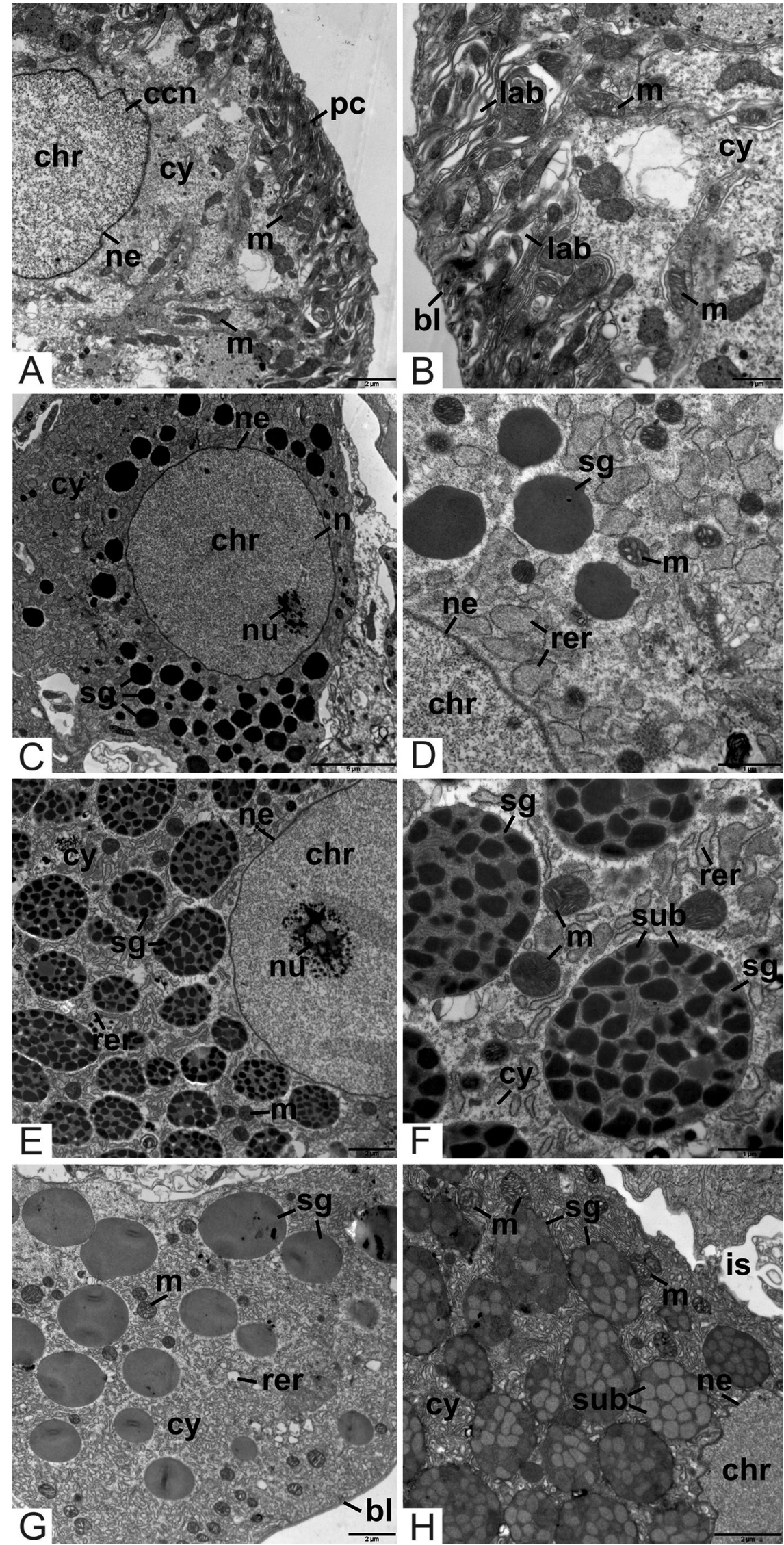

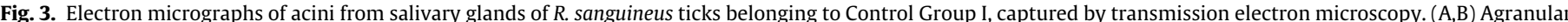

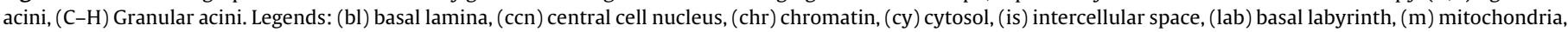

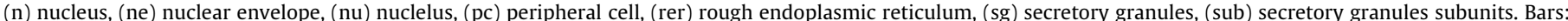
(A,E,G,H) $2 \mu \mathrm{m}$, (B,D,F) $1 \mu \mathrm{m}$, (C) $5 \mu \mathrm{m}$. 

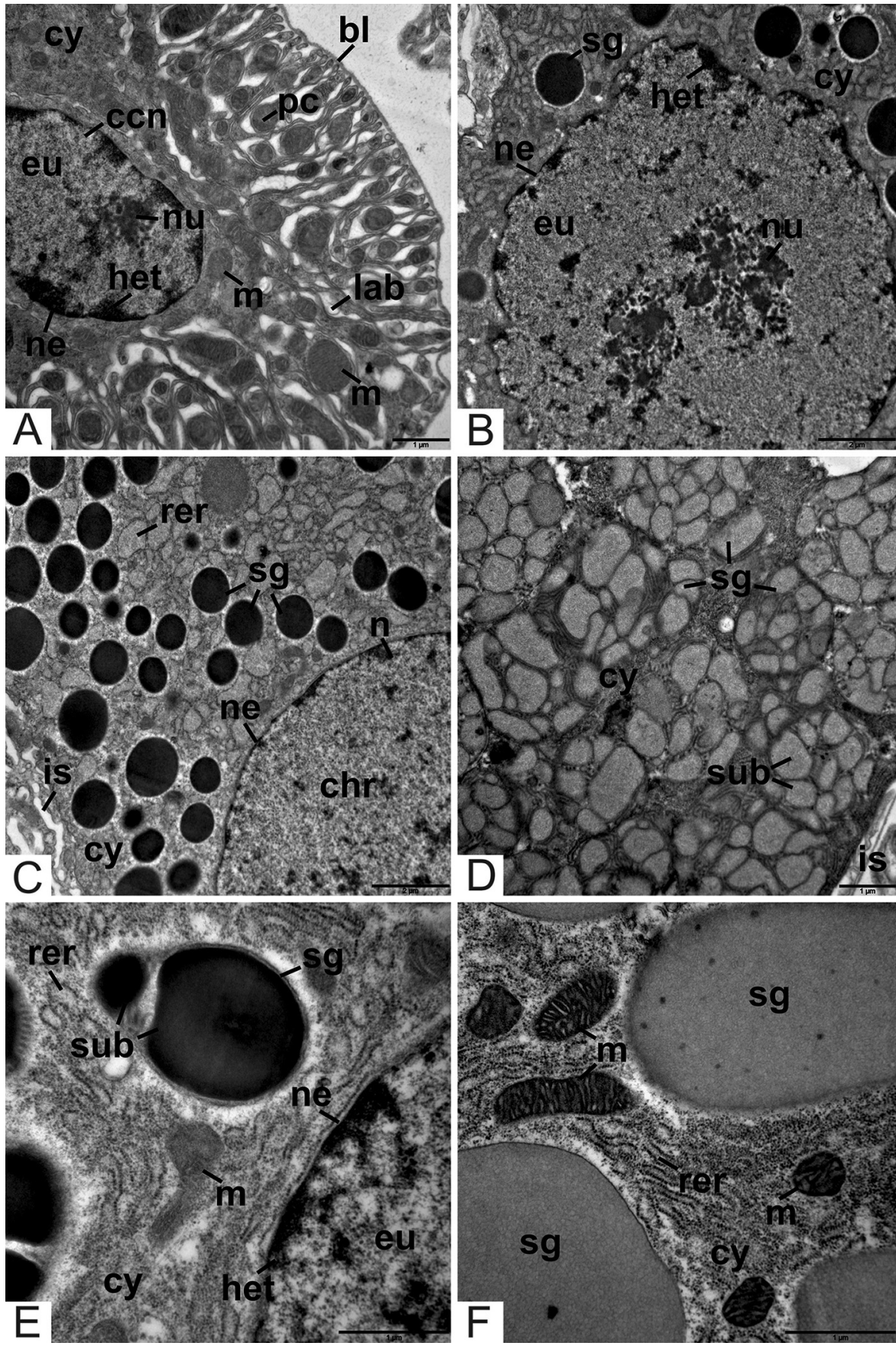

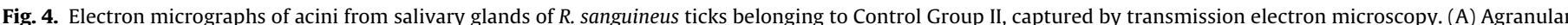

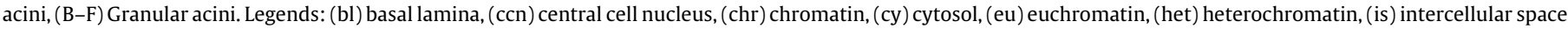

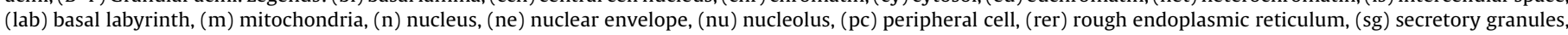
(sub) secretory granules subunits. Bars: (A,D-F) $1 \mu \mathrm{m},(\mathrm{B}, \mathrm{C}) 2 \mu \mathrm{m}$.

The morphophysiological study of salivary glands of ticks exposed to different chemical agents has been viewed as a fundamental tool in the development of control methods (Nodari et al., 2012b), considering the importance of feeding in the reproductive development of the ticks (Pereira et al., 2011). In the present study, the morphological alterations were more intense as the concentration of the substances increased, indicating a dosedependent effect. The histological evaluation of the ovaries of $R$. sanguineus ticks exposed to aqueous neem leaf extract also showed a dose-dependent pattern (Denardi et al., 2010) although it was not observed in the ultra-structural and histochemical analyses (Denardi et al., 2011, 2012). In addition, neem seed oil caused dose- dependent death to R. decoloratus (Choudhury, 2009), Amblyomma variegatum (Ndumu et al., 1999) and Hyalomma anatolicum excavatum ticks (Abdel-Shafy and Zayed, 2002).

Individuals belonging to the control groups presented salivary glands with typical morphology, as previously described for the species (Furquim et al., 2008a,b,c; Pereira et al., 2011). The absence of evident alterations in group CII suggests that ethanol at 10\% may be considered an adequate solvent, since it does not modify neem action.

According to Fawcett et al. (1986), the agranular acini probably maintain hydration of the tick during the fasting period. Also, they may act throughout the feeding process, secreting lipid for the 

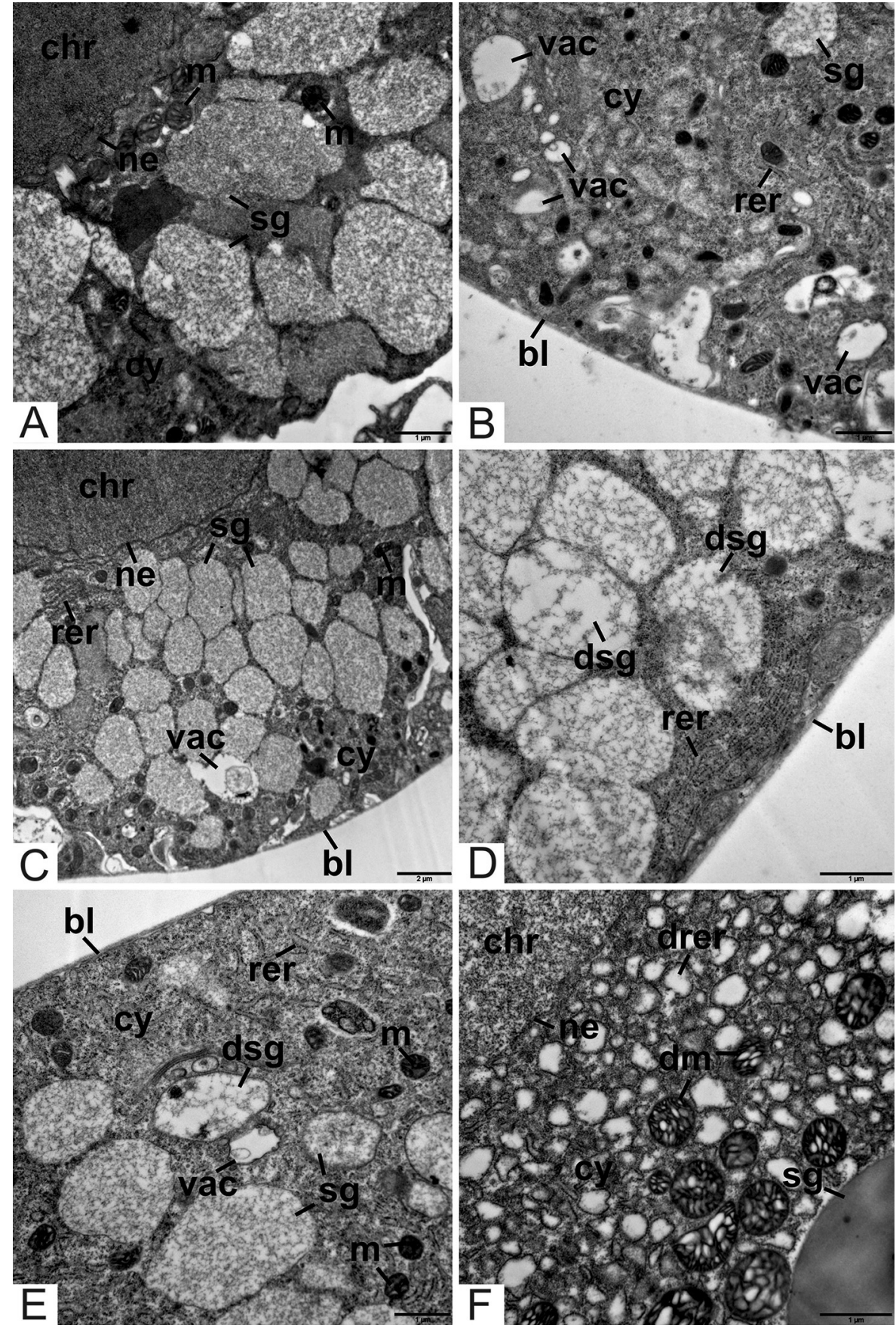

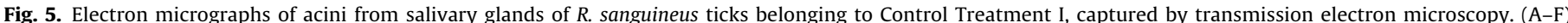

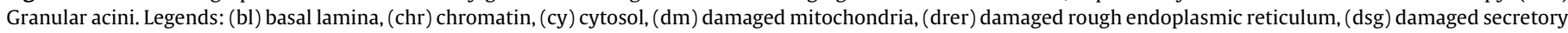
granule, (m) mitochondria, (ne) nuclear envelope, (rer) rough endoplasmic reticulum, (sg) secretory granules, (vac) vacuolation. Bars: (A,B,D-F) $1 \mu \mathrm{m}$, (C) $2 \mu \mathrm{m}$.

formation of the cement, and transporting water and electrolytes during the initial stages of blood ingestion (Fawcett et al., 1986). In the present study, the occurrence of irregularities in the nuclear membrane of central cells in agranular acini, as well as their cytoplasmic disorganization and vacuolation, were more evident in the individuals belonging to group TIII. In some extreme cases, the observation of cytosol components and organelles was not possible. Alterations in agranular acini have already been demonstrated in an experiment performed by Pereira et al. (2009), in which these structures showed significant increase in size and lumen diameter when semi-engorged $R$. sanguineus females were exposed to fipronil. Besides, when exposed to permethrin, type I acini of $R$. sanguineus demonstrated irregular shape, also with luminal dilation (Nodari et al., 2012a). Changes observed after exposure to $A$. indica oil, therefore, constitute clear signs of the toxic effects of this product, indicating its possible action on the physiology of the salivary gland. This may have compromised feeding among these ticks, affecting the process of concentration of ingested blood and, thus, hindering an effective absorption of nutrients.

Granular acini of female ticks consist of various cell types, which produce different substances and become active according to the feeding stage of ticks (Fawcett et al., 1986; Arnosti et al., 2013). It is believed that the granular material surrounded by membranes 

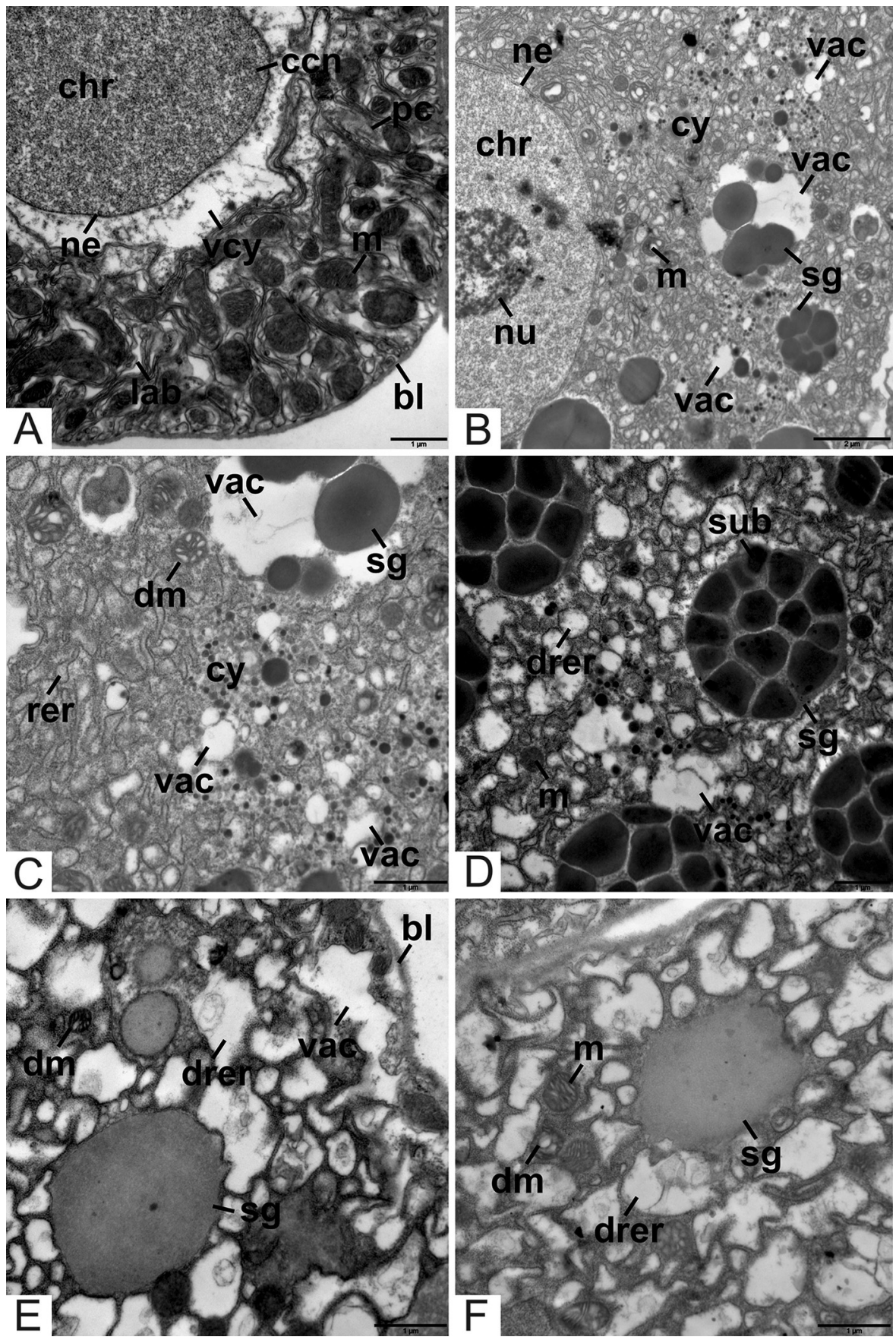

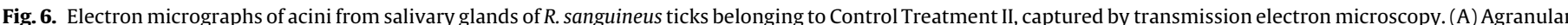

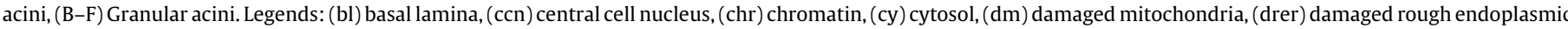

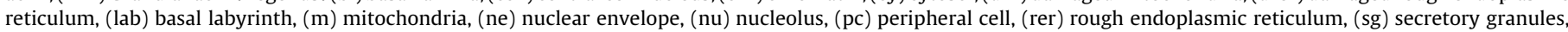
(sub) secretory granules subutnits, (vac) vacuolation, (vcy) vacuolated cytotol. Bars: (A,C-F) $1 \mu \mathrm{m}$, (B) $2 \mu \mathrm{m}$.

observed in these acini is the source of most bioactive protein components of ticks' saliva (Sauer et al., 2000).

In the granular acini of $R$. sanguineus treated with neem oil, the apparent fusion of secretory granules, observed in the histological analysis, was not confirmed by ultrastructural evaluation. This may be due to cytoplasmic disorganization and dilation of rough endoplasmic reticulum (RER), visualized at the ultrastructural level around the granules of secretory cells. Such alterations may have affected the visualization of granules in histology, so that they were observed as a mass of fused or disrupted granulations.

According to Nodari et al. (2011, 2012a,b), granular acini of $R$. sanguineus exposed to permethrin showed changes in their original form, and their surface became extremely wrinkled. At higher concentrations, disrupted acini were observed and they even formed amorphous masses consisting of cell debris. The treatment with neem oil in this study was also responsible for the occurrence of irregularities in acini surface.

In confocal microscopy analysis, the high staining intensity, mainly in the basal portion of the acinar cells in treated individuals, is probably due to a change in the characteristics of actin filaments in these cells. The disorganization of cytoskeletal elements has already been observed at the ultrastructural level and reported by Pereira et al. (2011), as a result of the toxic effect of fipronil on the salivary glands of $R$. sanguineus. In addition, aque- 

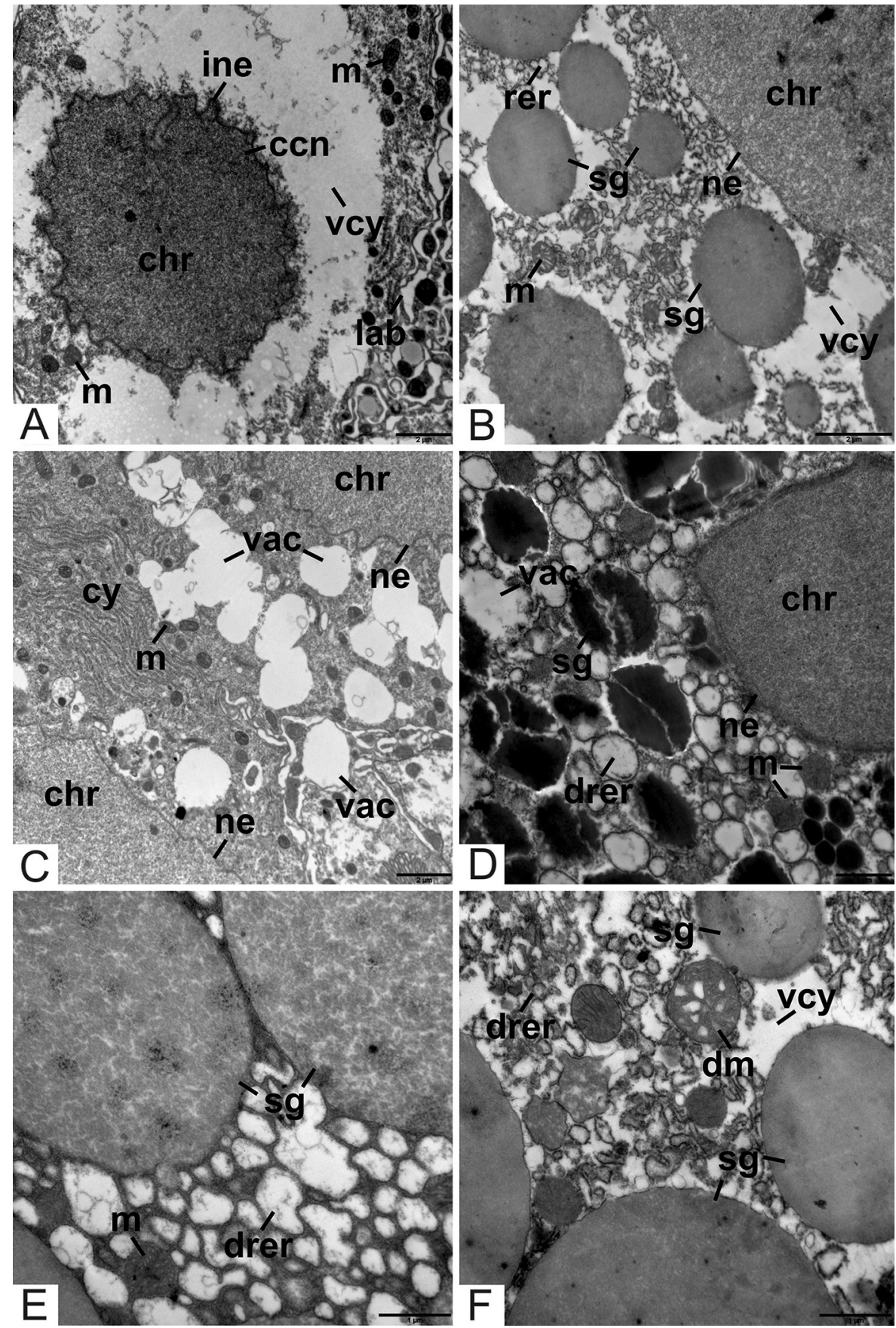

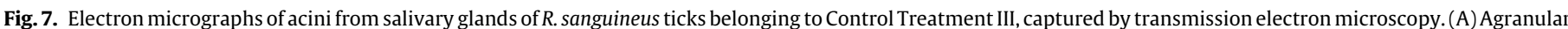

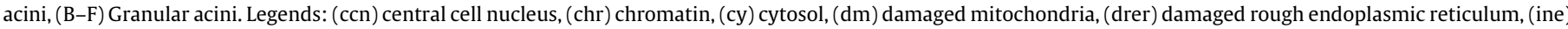

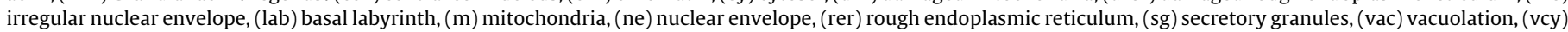
vacuolated cytosol. Bars: (A-C) $2 \mu \mathrm{m}$, (D-F) $1 \mu \mathrm{m}$.

ous neem leaf extracts have been responsible for these changes in oocytes of $R$. sanguineus ticks (Denardi et al., 2012), corroborating the results obtained here.

In general, exposure of cells to compounds with acaricidal properties leads to the occurrence of nuclear or nucleolar changes. In $R$. sanguineus treated with permethrin, granular acini cells exhibited severe and irreversible nuclear damage, such as changes in shape and size, fragmentation, pyknosis and chromatin marginalization (Nodari et al., 2011,2012b). Pereira et al. (2009, 2011) also observed similar nuclear changes in $R$. sanguineus ticks treated with fipronil. Besides, in groups exposed to the highest concentrations of fipronil, secretory cells exhibited a ring-shaped nucleolus. In our study, the exposure to the various concentrations of neem oil, however, did not cause any apparent nuclear or nucleolar abnormalities.

Treatment with neem oil, in this study, caused dilation of RER lamellae in granular acini of $R$. sanguineus, suggesting that protein synthesis in these cells may be impaired. According to Pereira et al. (2011), these changes, also observed in $R$. sanguineus treated with fipronil, might constitute a degenerative process indicating the occurrence of apoptotic cell death.

The dilated inter-membrane space of mitochondria in groups treated with neem oil may cause losses in energy production, affecting even more the synthesis of acini secretions. Mitochondrial swelling and degeneration were also observed in acinar cells of $R$. 
sanguineus treated with fipronil (Pereira et al., 2011). Moreover, in oocytes of ticks of the same species, exposure to aqueous extracts of neem leaves also caused morphological changes in the mitochondria, such as disruption or absence of mitochondrial cristae (Denardi et al., 2012).

In our study, vacuolization regions were ultrastructurally identified as strong electron-lucid regions, where cytoplasmic components were not observed. Similar histological changes were visualized in glandular acini of $R$. sanguineus exposed to fipronil (Pereira et al., 2009, 2011) and permethrin (Nodari et al., 2011, 2012a,b), showing that the effects of active ingredients present in neem are similar to those caused by administration of synthetic acaricides. These vacuolated regions might be, therefore, portions of cytosol damaged by the action of chemical compounds or even regions where the cytoplasmic components could be degraded or recycled, in order to keep viability and cell integrity (Denardi et al., 2012).

Tick contact to acaricides can accelerate cell death due to atypical apoptosis, as observed in acini of $R$. sanguineus ticks treated with fipronil (Pereira et al., 2009, 2011) and permethrin (Nodari et al., 2011, 2012a,b). In R. sanguineus exposed to neem, however, the absence of nuclear changes and apoptotic bodies weakened the evidence of early atypical apoptosis, although the dilation of RER lamellae has been described by Pereira et al. (2011) as a characteristic of apoptotic cell death.

\section{Conclusion}

The damages observed in salivary glands of $R$. sanguineus ticks exposed to neem oil may result in changes in the composition of saliva, compromising the ingestion of blood by the ticks. It is assumed, therefore, that continued exposure to $A$. indica seed oil may cause losses to the feeding behavior of these animals, leading to further damages regarding their reproductive development. These results reinforce the potential of neem oil in reproductive control of $R$. sanguineus ticks.

\section{Funding}

Coordenação de Aperfeiçoamento de Pessoal de Nível Superior (CAPES, Brazil) and Conselho Nacional de Desenvolvimento Científico e Tecnológico (CNPq, Brazil).

\section{Conflict of interest}

No conflicts of interest to declare.

\section{Acknowledgments}

The authors are thankful to Prof. Moacir Rossi Forim, Prof. Odair Correa Bueno and Marcela Ceccato for providing neem oil for the development of this work. This research was financially supported by CAPES (Coordenação de Aperfeiçoamento de Pessoal de Nível Superior) and CNPq (Conselho Nacional de Desenvolvimento Científico e Tecnológico).

\section{References}

Abdel-Shafy, S., Zayed, A.A., 2002. In vitro acaricidal effect of plant extract of neem seed oil (Azadirachta indica) on egg, immature, and adult stages of Hyalomma anatolicum excavatum (Ixodoidea: Ixodidae). Vet. Parasitol. 106, 89-96.

Alves, W.V., Lorenzetti, E.R., Gonçalves, F.C., 2012. Utilização de acaricidas a base de plantas no controle de Rhipicephalus (Boophilus) microplus: uma contribuição para a produção e desenvolvimento sustentável. Rev. Bras. Agropecu. Sustent. 2 (2), 14-25.

Arnosti, A., Sampieri, B.R., Pereira, C.P.M., Nunes, E.T., Calligaris, I.B., Furquim, K.C.S., Nunes, P.H., Brienza, P.D., Camargo-Mathias, M.I., 2013. Glândulas salivares. In: Camargo-Mathias, M.I. (Ed.), Guia Básico de Morfologia Interna de Carrapatos Ixodídeos. Editora UNESP, São Paulo, pp. pp. 39--74.

Atawodi, S.E., Atawodi, J.C., 2009. Azadirachta indica (neem): a plant of multiple biological and pharmacological activities. Phytochem. Rev. 8, 601-620.

Bechara, G.H., Szabó, M.P.J., Ferreira, B.R., Garcia, M.V., 1995. Rhipicephalus sanguineus tick in Brazil: feeding and reproductive aspects under laboratorial conditions. Braz. J. Vet. Parasitol. 4 (2), 61-66.

Blagburn, B.L., Dryden, M.W., 2009. Biology: treatment and control of flea and tick infestations. Vet. Clin. Small Anim. 39, 1173-1200.

Brahmachari, G., 2004. Neem-an omnipotent plant: a retrospection. ChemBioChem 5, 408-421.

Broglio-Micheletti, S.M.F., Dias, N.S., Valente, E.C.N., Souza, L.A., Lopes, D.O.P., Santos, J.M., 2010. Ação do extrato e óleo de nim no controle de Rhipicephalus (Boophilus) microplus (Canestrini, 1887) (Acari: Ixodidae) em laboratório. Rev. Bras. Parasitol. Vet. 19 (1), 44-48.

Carpenter, T.L., McMeans, M.C., Mchugh, C.P., 1990. Additional instances of human parasitism by the Brown dog tick (Acari: Ixodidae). J. Med. Entomol. 27 (6), 1065-1066.

Choudhury, M.K., 2009. Toxicity of neem seed oil against the larvae of Boophilus decoloratus: a one-host tick in cattle. Indian J. Pharm. Sci. 5, 562-563.

Cooper, J.A., 1987. Effects of cytochalasin and phalloidin on actin. J. Cell. Biol. 105, $1473-1478$.

Cunha, N.C., Fonseca, A.H., Rezende, J., Rozental, T., Favacho, A.R.M., Barreira, J.D., Massard, C.L., Lemos, E.R.S., 2009. First identification of natural infection of Rickettsia rickettsii in the Rhipicephalus sanguineus tick, in the state of Rio de Janeiro. Pesqui. Vet. Bras. 29 (2), 105-108.

Dantas-Torres, F., Figueiredo, L.A., Brandão-Filho, S.P., 2006. Rhipicephalus sanguineus (Acari: Ixodidae), the Brown dog tick, parasiting humans in Brazil. Rev. Soc. Bras. Med. Trop. 39 (1), 64-67.

Dantas-Torres, F., 2010. Biology and ecology of the Brown dog tick, Rhipicephalus sanguineus. Parasites Vectors 3 (26), 1-11.

Denardi, S.E., Bechara, G.H., Oliveira, P.R., Camargo-Mathias, M.I., 2010. Azadiracht indica A. Juss (neem) induced morphological changes on oocytes of Rhipicephalus sanguineus (Latreille, 1806) (Acari Ixodidae) tick females. Exp. Parasitol. 126, 462-470.

Denardi, S.E., Bechara, G.H., Oliveira, P.R., Camargo-Mathias, M.I., 2011. Inhibitory action of neem aqueous extract (Azadirachta indica A. Juss) on the vitellogenesis of Rhipicephalus sanguineus (Latreille, 1806) (Acari Ixodidae) ticks. Microsc. Res. Tech. 74, 889-899.

Denardi, S.E., Bechara, G.H., Oliveira, P.R., Camargo-Mathias, M.I., 2012 Ultrastructural analysis of the oocytes of female Rhipicephalus sanguineus (Latreille, 1806) (Acari: Ixodidae) tick subjected to the action of Azadirachta indica A. Juss (neem). Ultrastruct. Pathol. 1, 56-67.

Fawcett, D.W., Binnington, K., Voigt, W.P., 1986. The cell biology of the ixodid tick salivary gland. In: Sauer, J.R., Hair, A. (Eds.), Morphology, Physiology, and Behavioral Biology of Ticks, 470p. Halsted Press: John Wiley \& Sons, New York.

Flamini, G., 2003. Acaricides of natural origin: personal experiences and review of literature (1990-2001). Stud. Nat. Prod. Chem. 28, 381-451.

Forim, M.R., Silva, M.F.G.F., Cass, Q.B., Fernandes, J.B., Vieira, P.C., 2010. Simultaneous quantification of azadirachtin and 3-tigloylazadirachtol in Brazilian seeds and oil of Azadirachta indica: application to quality control and marketing. Anal. Method 2, 860-869.

Furquim, K.C.S., Bechara, G.H., Camargo-Mathias, M.I., 2008a. Cytoplasmic RNA and nuclear changes detected cytochemically during the degeneration of salivary glands of the tick Rhipicephalus sanguineus (Latreille, 1806) (Acari: Ixodidae). Micron 39, 960-966.

Furquim, K.C.S., Bechara, G.H., Camargo-Mathias, M.I., 2008b. Degeneration of salivary glands of males of the tick Rhipicephalus sanguineus (Latreille: 1806) (Acari: Ixodidae). Vet. Parasitol. 154, 325-335

Furquim, K.C.S., Bechara, G.H., Camargo-Mathias, M.I., 2008c. Death by apoptosis in salivary glands of females of the tick Rhipicephalus sanguineus (Latreille: 1806) (Acari: Ixodidae). Exp. Parasitol. 119, 152-163.

Jonjejan, F., Uilenberg, G., 2004. The global importance of ticks. Parasitology 129, S3-S14.

Junqueira, L.C.U., Junqueira, L.M.M.S., 1983. Técnicas Básicas de Citologia e Histologia. Editora Santos, São Paulo, pp. 124.

Manfredi, M.T., Dini, V., Piacenza, S., Genchi, C., 1999. Tick species parasitizing people in an area endemic for tick-borne diseases in North-western Italy. Parasitologia 41 (4), 555-560.

Ndumu, P.A., George, J.B.D., Choudhury, M.K., 1999. Toxicity of neem seed oil (Azadirachta indica) against the larvae of Amblyomma variegatum a three-host tick in cattle. Phytother. Res. 13, 532-534.

Nodari, E.F., Roma, G.C., Furquim, K.C.S., Bechara, G.H., Camargo-Mathias, M.I., 2011. Cytotoxic effects of permethrin in salivary glands of Rhipicephalus sanguineus (Latreille, 1806) (Acari: Ixodidae) semi-engorged females. Exp. Parasitol. 128, 151-158.

Nodari, E.F., Roma, G.C., Furquim, K.C.S., Bechara, G.H., Camargo-Mathias, M.I., 2012a. Action of permethrin on Rhipicephalus sanguineus (Latreille: 1806) (Acari: Ixodidae) semi-engorged females: morpho-physiological evaluation of salivary glands. Ticks Tick Borne Dis. 3, 219-226.

Nodari, E.F., Roma, G.C., Furquim, K.C.S., Oliveira, P.R., Bechara, G.H., Camargo-Mathias, M.I., 2012b. Degenerative process and cell death in salivary glands of Rhipicephalus sanguineus (Latreille: 1806) (Acari: Ixodidae) semi-engorged female exposed to the acaricide permethrin. Microsc. Res. Tech. 75, 1012-1018. 
Pereira, C.P., Oliveira, P.R., Furquim, K.C.S., Bechara, G.H., Camargo-Mathias, M.I 2009. Effects of fipronil (active ingredient of Frontline ${ }^{\circledR}$ ) on salivary gland cells of Rhipicephalus sanguineus females (Latreille, 1806) (Acari Ixodidae). Vet. Parasitol. 166, 124-130.

Pereira, C.P., Oliveira, P.R., Furquim, K.C.S., Bechara, G.H., Camargo-Mathias, M.I., 2011. Fipronil-induced cell death in salivary glands of Rhipicephalus sanguineus (Latreille, 1806) (Acari: Ixodidae) semi-engorged females. Exp. Parasitol. 127, 481-489.

Remedio, R.N., Nunes, P.H., Anholeto, L.A., Camargo-Mathias, M.I., 2014 Morphological alterations in the synganglion and integument of Rhipicephalus sanguineus ticks exposed to aqueous extracts of neem leaves (Azadirachta indica A Juss). Microsc. Res. Tech. 77, 989-998.

Remedio, R.N., Nunes, P.H., Anholeto, L.A., Oliveira, P.R., Camargo-Mathias, M.I., 2015. Morphological effects of neem (Azadirachta indica A. Juss) seed oil with known azadirachtin concentrations on the oocytes of semi-engorged Rhipicephalus sanguineus ticks (Acari Ixodidae). Parasitol. Res. 114, 431-444.

Reynolds, E.S., 1963. The use of lead citrate at high pH eletron-opaque stain in electron microscopy. J. Cell Biol., 208-212.

Rosado-Aguilar, J.A., Aguilar-Caballero, A., Rodriguez-Vivas, R.I., Borges-Argaez, R. Garcia-Vazquez, Z., Mendez-Gonzalez, M., 2010. Acaricidal activity of extracts from Petiveria alliacea (Phytolaccaceae) against the cattle tick: Rhipicephalus (Boophilus) microplus. Vet. Parasitol. 168, 299-303.
Sauer, J.R., Mcswain, J.L., Bowman, A.S., Essenberg, R.C., 1995. Tick salivary gland physiology. Annu. Rev. Entomol. 40, 245-267.

Sauer, J.R., Essenberg, R.C., Bowman, A.S., 2000. Salivary glands in ixodid ticks: control and mechanism of secretion. J. Insect Physiol, 46, 1069-1078.

Schmutterer, H., 1990. Properties and potential of natural pesticides from the neem tree Azadirachta indica. Annu. Rev. Entomol. 35, 271-297.

Suzuki, T., Fujikura, K., Higashiyama, T., Takatam, K., 1997. DNA staining for fluorescence and laser confocal microscopy. J. Histochem. Cytochem. 45 (1), 49-53.

Srivastava, R., Ghosh, S., Mandal, D.B., Azhahianambi, P., Singhal, P.S., Pandey, N.N., Swarup, D., 2008. Efficacy of Azadirachta indica extracts against Boophilus microplus. Parasitol. Res. 104, 149-153.

Uspensky, I., Ioffe-Uspensky, I., 2002. The dog factor in Brown dog tick Rhipicephalus sanguineus (Acari: Ixodidae) infestations in and near human dwellings. Int. J. Med. Microbiol. 33, 156-163.

Vietmeyer, N.D., 1992. Neem: a tree for solving global problems. Report of an ad hoc panel of the Board on Science and Technology for International Development. National Academy Press Washington, D.C., 152 p. 